\title{
Estado y política agraria en la frontera sur argentina: el territorio nacional de Río Negro (1916-1930)
}

\author{
Martha Ruffini*
}

\begin{abstract}
Resumen. En 1916 asumió la presidencia de la República Argentina Hipólito Yrigoyen, líder del partido Unión Cívica Radical (1916-1930), quien motorizó una política pretendidamente reparadora del "orden conservador" precedente. La implementación de la reparación en los territorios nacionales -verdaderas fronteras interiores del Estado nacional- se vio facilitada por la centralización política y administrativa de estos espacios, resultando un prisma adecuado para interpretar el comportamiento estatal, sus intereses y sus motivaciones. En este artículo nos proponemos analizar la relación Estado-territorios mediante un estudio de caso: el territorio nacional de Río Negro, situado en el norte de la Patagonia, espacio de antiguo poblamiento de la frontera sur, que desde su creación requirió de la decisión estatal para superar los factores condicionantes para el desarrollo agropecuario. Empero, el gobierno radical no se apartaría de la política agraria desarrollada hasta entonces y evidenciaría dificultades para subsanar las cuestiones básicas obstaculizadoras del desarrollo, vinculadas con la navegabilidad del río Negro, y sus inundaciones periódicas, destructivas de todo intento de desarrollo agrario sostenido.
\end{abstract}

Palabras clave: estado, política, territorio, agro-frontera.

Abstract. The president Hipólito Yrigoyen, leader of the Radical Civic Union party (1916-1930), took office in 1916. He promoted a policy which supposedly pretended to rectify the previous "conservative order". The implementation of such policy in the national territories -real internal borders of the National State- was easier due to the administrative and political centralization of those territories, resulting in an appropriate perspective to interpreter the State's conduct as well as its interests and motivations. In this article we intended to analyze the State-territories relation through a case study: the National Territory of Río Negro, a very old inhabited place on the south border, in the north of the Patagonia, which since its establishment needed the State's decision to get through the determining factors for the agricultural development.

Nevertheless, the radical government would not get away from the prevailing agricultural policy and would show difficulties in overcoming certain obstacles, related to the navigability of the river Negro and its periodic floods, destructive of any sustainable farming progress.

Keywords: State, policy, territory, farming, border.

* Profesora regular e investigadora de la Universidad Nacional del Comahue. Investigadora del Centro de Estudios Históricos del Estado, Política y Cultura (CEHEPyC), centro miembro del Consejo Latinoamericano de Ciencias Sociales (Clacso). Investigadora Externa del Centro de Estudios Histórico Rurales (CEHR) de la Universidad Nacional de La Plata, República Argentina. Correos electrónicos: meruffini @gmail.com y martha_ruffini@yahoo.com.ar 


\section{A modo de introducción ${ }^{1}$}

En este artículo analizaremos la política agraria desarrollada por el Estado argentino para los territorios nacionales a través de un estudio de caso: el territorio nacional de Río Negro, ubicado en la frontera sur, al norte de la región conocida como la Patagonia argentina.

La pertinencia de un estudio acerca de la política agraria en espacios centralizados permite advertir los límites y alcances efectivos de la política económica, ya que fueron creados en un momento de expansión del modelo primario exportador (1860-1930) y la posibilidad que articularan sus producciones con el paradigma vigente constituía un resorte exclusivo del Estado nacional. Asimismo, el Estado como relación social de fuerzas refleja en su conformación y actividades los intereses de los sectores dominantes pero también recibe influencia de las demandas y acciones de otros sectores y grupos sociales. Por ello, el análisis de la política agraria estatal como parte de las acciones coherentes o contradictorias desplegadas por el Estado nacional en un espacio determinado para consolidar o atenuar el modo de acumulación dominante (Astori, 1984:163) será un aspecto a considerar en este artículo.

El territorio rionegrino constituyó el espacio poblado más antiguo de la frontera sur, ya que se originó a partir de la creación del Fuerte El Carmen (1779) en el marco de la política defensiva desplegada por la dinastía borbónica para el litoral marítimo del virreinato del Río de la Plata (1776-1810).

A partir de 1878, el Estado nacional asumió el control político y militar de la Patagonia. En Río Negro gran parte del territorio requería de la acción estatal para superar los factores condicionantes para el desarrollo agropecuario. Sin embargo, durante la vigencia del "orden conservador" (1880-1916) la acción estatal se limitó a la zona co-

\footnotetext{
${ }^{1}$ Una versión preliminar de este trabajo fue presentada en el $1^{\circ}$ Congreso Latinoamericano de Historia Económica, desarrollado en la Universidad de la República (Montevideo, Uruguay) del 5 al 7 de diciembre del 2007. Agradezco los comentarios de las doctoras Noemí Girbal (Universidad Nacional de Quilmes/CONICET-República Argentina), María Cecilia Zuleta (Universidad Autónoma Metropolitana de Iztapalapa-México) y Sonia Mendonça (Universidad Federal Fluminense-Brasil).
} 
nocida como "alto valle" (norte del territorio), instalándose en 1899 el ferrocarril mediante la asociación con el capital inglés e iniciándose obras de riego que impulsaron la producción vitivinícola y frutícola de la región. En los restantes territorios nacionales el Estado operó de manera similar, potenciando la producción primaria de bajo costo y alta rentabilidad como el caso del algodón y la madera en los territorios de Chaco y Formosa o la ganadería en la zona este del territorio de La Pampa.

En 1916 el cambio de signo político, revelador de la crisis del modo de dominación oligárquico del régimen conservador, abrió un horizonte de expectativas centrado en la posibilidad de modificar la condición subordinada -tanto política como económica- de los territorios nacionales. La idea de "reparación" que el líder radical Hipólito Yrigoyen utilizó como bandera de la campaña electoral, implicaba subsanar los errores de la etapa conservadora y propiciar la inclusión de la totalidad del cuerpo social. Esta inclusión era política pero también económica mediante la concreción de inversiones estatales que aseguraran un crecimiento sostenido de diferentes regiones hasta entonces postergadas, como los territorios nacionales del sur. Sin embargo, parecería que el gobierno de la Unión Cívica Radical (1916-1930)² a pesar de su declamación discursiva presentó limitaciones evidentes para poder realizar la ruptura enunciada y diferenciarse de las acciones desarrolladas por el régimen precedente. En Río Negro no innovaría sustancialmente en la política agraria, dejando sin resolución las cuestiones fundamentales que obstaculizaban el desarrollo agrícola en la zona atlántica o del llamado "valle inferior" del territorio rionegrino.

En líneas generales carecemos de estudios en el largo plazo sobre la política estatal agraria para los territorios en general y para Río Negro en particular. Las obras que se ocuparon de la etapa territorial

\footnotetext{
2 En 1916 y merced a la reforma del sistema electoral en 1912, el partido Unión Cívica Radical obtuvo la presidencia de la nación con la fórmula Hipólito YrigoyenPelagio Luna. En 1922 le sucedió en el gobierno nacional otro radical, Marcelo T. de Alvear (1922-1928), y en 1928 se inició el segundo gobierno de Yrigoyen, interrumpido el 6 de septiembre de 1930 por un golpe de Estado con apoyo civil, encabezado por los generales José Félix Uriburu y Agustín P. Justo.
} 
otorgaron a la economía un lugar relevante aunque sin presentar una visión integral tanto de la acción del Estado como de la persistencia o superación de elementos obstaculizadores del desarrollo (Rey y Vidal, 1974; Toldo, 1980; Rey et al. 1987; Navarro Floria y Nicoletti, 2000). En cuanto a trabajos más específicos, el estudio de Noemí Girbal (1976:5859) sobre la agricultura rionegrina señaló la orientación ganadera del territorio y la necesidad de obras de irrigación para concretar la expansión agrícola en los valles.

Para contextualizar adecuadamente el objeto de estudio reseñaremos brevemente los antecedentes vinculados con la organización estatal, el problema de la frontera y la creación de los territorios nacionales en 1884. Para posibilitar una mejor comprensión de la política agraria, se explicitarán las facultades atribuidas al Estado nacional en lo atinente al desarrollo económico de los territorios nacionales. En el estudio de caso, centraremos la atención en los factores limitantes para el desarrollo agropecuario, aspecto necesario para articular con el modelo agroexportador y las acciones desarrolladas por el gobierno de la Unión Cívica Radical (1916-1930) en este sentido.

\section{La construcción del Estado nacional y la organización territorial}

A principios del siglo XIX la crisis del imperio español se tradujo en América hispana en el quiebre de la dominación colonial y la guerra por la independencia. A partir de la Revolución de 1810, el ex virreinato del Río de La Plata ${ }^{3}$ inició un proceso de fragmentación y disolución de las estructuras políticas, sociales y económicas heredadas de los españoles, al mismo tiempo que la revolución impulsada por la élite criolla ponía en marcha el proceso de construcción del Estado argentino.

La etapa formativa del Estado argentino (1810-1880) estuvo signada por la búsqueda de nuevas formas de legitimación política que justificaran el orden naciente y permitieran diseñar un Estado nacional. Los sucesivos intentos de organizar a la nación bajo el signo republicano a

\footnotetext{
${ }^{3}$ El virreinato del Río de La Plata fue creado en 1776 con capital en la ciudadpuerto de Buenos Aires. Abarcaba los actuales países de Argentina, Uruguay, Paraguay, norte de Chile, sur de Bolivia y Brasil.
} 
través de ensayos constitucionales fueron impulsados por los diferentes gobiernos provisionales, tanto colegiados como unipersonales que se sucedieron durante la primera década revolucionaria. ${ }^{4}$

Ante la ausencia de una nación preexistente (Chiaramonte, 1995:159), los grupos dirigentes de la poderosa ciudad de Buenos Aires se hallaron ante el dilema de definir una soberanía única rioplatense o respetar la autonomía de los gobiernos locales. A partir de 1820 y una vez disuelta la frágil estructura de las Provincias Unidas, se impuso el formato provincial como cristalización de las soberanías locales emergentes. El pacto constitucional proclamado en 1853 adoptó la forma de gobierno republicana, representativa y federal, siendo las provincias autónomas la organización predominante en el Estado argentino.

Pero una parte del territorio argentino no quedó organizada en provincias. Eran zonas aisladas, ubicadas en el sur y nordeste del país, de escasa población, que se hallaban bajo el dominio de los pueblos indígenas, conjunto heterogéneo de etnias con diferente grado de belicosidad que resistían los intentos de ocupación y poblamiento de las provincias aledañas. ${ }^{5}$

En el marco de la lucha por el poder entre el Estado naciente y las provincias autónomas (Ruffini, 2007:29 y ss), colocar bajo la égida estatal a las llamadas "tierras nacionales" constituyó una asignatura pendiente por largo tiempo. No sólo porque las provincias limítrofes consideraban que tenían derechos adquiridos al haber ejercido acciones de exploración, poblamiento y entrega de tierras, ${ }^{6}$ sino porque al

\footnotetext{
${ }^{4}$ Los gobiernos centrales provisorios de las Provincias Unidas del Río de La Plata (1810-1820) fueron inicialmente de carácter colegiado: Primera Junta, Junta Grande, Primer y Segundo Triunvirato. En 1814 se creó el primer gobierno unipersonal argentino: el Directorio (1814-1820). En 1819 y 1826 se dictaron sendas constituciones nacionales de carácter unitario apoyadas por los sectores dirigentes de Buenos Aires, pero que fueron rechazadas por las provincias del interior.

${ }^{5}$ Según Silvia Ratto (2007), la heterogeneidad del mundo indígena implicaba diferentes modos de vida y de relación, razón por la que el patrón de asentamiento de los pueblos de Pampa y Patagonia era muy diferente. En la Patagonia habitaron los mapuches, los pehuenches (zona cordillerana) y los tehuelches ubicados al sur del río Colorado.

${ }^{6}$ A modo de ejemplo, la provincia de Corrientes había incorporado la zona de las Misiones en 1827 para administrarla. Firmó tratados de paz con los indígenas,
} 
estar bajo dominio indígena resultaba indispensable generar un consenso amplio acerca de la modalidad a adoptar para resolver el llamado "problema de la frontera".

Como se ha afirmado, las políticas desarrolladas desde 1810 promovieron la expansión territorial hacia el sur para incorporar tierras para la ganadería. Las incursiones militares hacia el interior del mundo indígena coexistieron con sucesivos malones como respuesta al intento de avance del gobierno central (Ratto, 2007).

El dilema a elucidar era consensuar la modalidad más eficaz de extender la soberanía nacional. Distintas posiciones postergaron la resolución del problema y originaron propuestas de diferente tenor, que variaron desde el llamado "negocio pacífico con los indios" entre 1829 y 1852, la política de tratados de paz desde la segunda mitad del siglo XIX, el reforzamiento del sistema defensivo sostenido por una línea de fuertes y fortines, hasta confluir finalmente en la campaña militar de exterminio y sojuzgamiento del mundo indígena realizada entre 1879 y 1885 . Como se ha afirmado, la cuestión indígena se relacionó estrechamente con el proceso más amplio de construcción del Estado nacional y una sociedad capitalista (Mases, 2002:20).

Una vez neutralizado el peligro indígena, los espacios de frontera fueron organizados como territorios nacionales, entidades políticoadministrativas dependientes del poder central, carentes de autonomía y con habitantes que portaban derechos políticos restringidos. ${ }^{7}$

fundó poblaciones y entregó tierra pública. Desde 1820 la provincia de Buenos Aires había integrado como dominio propio a toda la Patagonia argentina. Obviamente esta soberanía fue más nominal que real, aunque en la margen sur del río Negro se habían instalado autoridades y se aplicaron los decretos y leyes de tierras provinciales de 1821 y 1855. También la provincia de Salta había legislado sobre el territorio de Formosa a partir de 1857.

${ }^{7}$ Los territorios nacionales creados en 1884 fueron Chaco, Formosa, Misiones, La Pampa, Río Negro, Chubut, Santa Cruz y Tierra del Fuego. En 1900 se creó la gobernación de Los Andes, que en 1943 fue suprimida y su espacio repartido entre las provincias de Salta, Jujuy y Catamarca. Observando el mapa ubicado al final del artículo, advertimos que los diez territorios nacionales ocupaban un tercio de la superficie de la República Argentina. Sus habitantes no podían participar de las elecciones para presidente y legisladores nacionales (diputados y senadores) y sólo votaban en localidades con población superior a mil habitantes, en las que se podía instalar un municipio y juzgado de paz electivo. También tenían negado el derecho de representación ante el Congreso Nacional. 
$\mathrm{Al}$ igual que en otros países americanos, ${ }^{8}$ la creación de territorios nacionales constituyó una estrategia transicional destinada a establecer el control estatal sobre espacios considerados por la élite dirigente como "carentes de civilización". Las fronteras con el indígena fueron ahora reemplazadas por verdaderas "fronteras interiores", casi colonias internas dentro del mismo territorio.

Según la concepción dominante, se había eliminado y ganado para la civilización la tierra bajo dominio indígena. Pero la idea de "frontera" no había desaparecido: el límite, el "otro diferente" lo señalaba ahora la ignorancia, la barbarie, la carencia de contacto civilizador de la población que habitaba esos espacios, que los hacía pasibles de acciones estatales de homogeneización cultural y social.

En Argentina los territorios nacionales constituyeron un apéndice del Estado nacional, un espacio unitario en una República pretendidamente federal, un lugar para el despliegue de la burocracia estatal. Por su mismo carácter dependiente toda iniciativa sobre ellos quedaba limitada al Estado, siendo éste el principal protagonista de su crecimiento económico, social y cultural.

\section{El Estado argentino y sus "fronteras interiores"}

El origen de la titularidad estatal sobre los territorios nacionales proviene de la etapa constitucional. En el texto sancionado en 1853 se mencionó a los espacios exteriores a las provincias y bajo dominio

\footnotetext{
${ }^{8}$ Estados Unidos fue el primer país americano en organizar las zonas de frontera como territorios (1784). México tuvo territorios federales en el siglo XIX: Alta California (1824-1974), Baja California (1824-1952), Colima (1824-1857) y Santa Fe de Nuevo México. Tlaxcala fue territorio federal desde 1824 y entre 1856-1857; en 1902 México incorporó a Quintana Roo como territorio federal hasta 1974. En 1868 Colombia tuvo su primer territorio nacional (Casanare), al que le siguieron ocho territorios más: San Martín, Bolívar, Sierra Nevada, Motilones, Goajira, San Luis, Providencia, San Andrés. A partir de 1884 Venezuela tuvo dos territorios: Amazonas y Delta del Amacuro. Brasil obtuvo en 1903 el territorio del Acre, merced al Tratado de Petrópolis, y en 1942 Fernando de Noronha, Roraima y Amapá fueron territorios nacionales. Cabe aclarar que si bien compartían el carácter centralizado y la existencia de derechos políticos restringidos para sus habitantes, su organización y administración así como su autonomización implicó procesos diferenciados en cada país.
} 
indígena con el nombre de "tierras nacionales", denominación que ya de por sí preanunciaba conflictos, debido a las acciones de ocupación, poblamiento y penetración militar realizadas por las provincias cercanas a estos espacios.

En 1862 las tierras en disputa fueron declaradas de propiedad estatal mediante la Ley de Nacionalización de los Territorios. A partir de ese momento el Estado nacional se autoarrogó el exclusivo dominio sobre estos espacios convirtiéndose en el responsable excluyente de su organización y desarrollo.

En este contexto, la primera medida de carácter organizativo fue la creación de gobernaciones militares centralizadas. ${ }^{9}$ Pero la necesidad de incorporación de tierras para sostener el modo de acumulación dominante ${ }^{10}$ hacía imperioso el ejercicio de una soberanía plena sobre las llamadas "tierras nacionales". La conquista militar iniciada en 1879 incorporó casi 40 millones de hectáreas al patrimonio nacional, poniendo bajo el dominio estatal la zona sur del país -la mítica Patagonia argentina- que pudo ser ocupada y organizada libremente por el Estado nacional.

En 1884 el Estado argentino, sobre la base de las gobernaciones militares existentes, decidió la creación de los territorios nacionales. En virtud de su rango de "espacios carentes de civilización", "lugares de la barbarie", el Estado nacional ejercía un papel tutelar y monitoreaba su desarrollo moral y material con el fin de preservar en ellos el orden y la seguridad necesarios para evitar conflictos y homogeneizar a la población adaptándola a las pautas de civilización y los principios de nacionalidad imperantes.

\footnotetext{
${ }^{9}$ En 1872 se creó la Gobernación Militar del Chaco, en 1878 la Gobernación de la Patagonia y en 1881 la Gobernación Militar de Misiones. Constituyeron ensayos previos al estadio territorial que sirvieron para que el gobierno demostrara que podía administrar sin demasiada dificultad espacios aislados y a considerable distancia de la sede del gobierno nacional.

${ }^{10}$ Entre 1860 y 1930 Argentina -al igual que otros países de América Latinaadoptó como modelo económico de crecimiento el paradigma agroexportador, realizado sobre la base de la agricultura cerealera extensiva y la cría e invernada de ganado para los frigoríficos. La región de la pampa húmeda resultó la principal beneficiaria de este modelo, que articuló con algunas agroindustrias del interior como la vitivinícola en la zona oeste del país, la azucarera en el norte y la maderera en el nordeste.
} 
En los territorios nacionales el Estado fue entonces el principal decisor y protagonista: su poder operaba sobre todas las esferas de la vida territorial. El gobernador del territorio actuaba prácticamente como un mero delegado que debía vigilar el cumplimiento efectivo de la ley y garantizar la vida y seguridad de los habitantes. Con facultades mínimas y persistente vigilancia estatal, era un ejecutor pasivo de las órdenes del gobierno central, papel asignado como una estrategia preventora del posible involucramiento de esta autoridad con la sociedad local o para evitar su participación y decisión en los conflictos (Ruffini, 2007).

En un país de base agropecuaria el papel del Estado en el proceso de expansión capitalista resulta innegable como condición básica para tornar posible la acumulación. Los territorios nacionales, en los que el Estado pudo operar sin las dificultades que el enquistamiento de caudillos y redes de poder locales le imponían en las provincias, constituyen un prisma adecuado para observar con menor opacidad la naturaleza y el comportamiento del metapoder estatal.

Insertar a los territorios nacionales en el paradigma agroexportador podía constituir una opción estratégica que permitiría -en el corto plazo- postergar el inevitable límite de la expansión horizontal agraria con la incorporación y distribución de las tierras arrebatadas a los indígenas garantizando así la continuidad del modo de acumulación dominante. En los territorios la burguesía nacional, asociada estrechamente con el Estado, hallaría así una posibilidad segura y protegida para participar de inversiones rentables en el corto plazo.

Pero integrarlos al mercado requería no sólo centrarse en la tierra y las inversiones sino potenciar a los territorios como nuevas zonas económicas, elección que implicaba un fuerte compromiso estatal con su desarrollo y crecimiento futuro. Evidentemente, el Estado podría optar por aplicar un criterio selectivo y privilegiar aquellas zonas de rápido rendimiento económico -el este ganadero de La Pampa, el Chaco forestal- en las que no era necesaria una inversión importante para obtener rentabilidad en poco tiempo. Pero no todos los territorios eran potencialmente capaces de incorporarse al mercado internacional como productores agropecuarios. Requerían de la intervención del Estado para poner en producción las tierras y acortar las distancias que posi- 
bilitaran el transporte de productos. El Estado debía trazar caminos, construir puentes, instalar ferrocarriles, obras de riego, diques, puertos y edificios públicos para las autoridades y para la educación. En los territorios todo estaba por hacerse y el "brazo largo del Estado" (Oszlak, 1990) debía llegar hasta ellos para generar las condiciones necesarias para propiciar su crecimiento.

\section{Los factores limitantes para el desarrollo agrícola en Río Negro}

Como ya expresamos, Río Negro era uno de los territorios del sur que requería de una presencia estatal activa y una importante inversión en infraestructura para potenciar su crecimiento económico y su desarrollo agrícola.

Dentro del conjunto patagónico, el territorio de Río Negro presentó una notable diversidad geomorfológica. El lápiz del legislador había agrupado en esta entidad zonas de diferente trayectoria histórica y desigual capacidad económica: la zona andina, atlántica, el valle y la meseta, aisladas entre sí por grandes distancias. El Estado podía potenciar una zona sobre otra, subsanar este desequilibrio regional, atenuarlo o acentuarlo.

Pero Río Negro ofrecía un atractivo adicional: era -del conjunto de territorios patagónicos- el único que presentaba potencialidad para el desarrollo agrícola. La existencia de un curso fluvial de 600 kilómetros de largo que lo atraviesa casi en su totalidad permitía avizorar las posibilidades del desarrollo agropecuario basado en la agricultura de regadío en los valles del río Negro complementada con la ganadería extensiva que se practicaba desde la etapa colonial. Pero las frecuentes crecientes del río Negro, transmutadas en ocasiones en inundaciones catastróficas, debían ser reguladas con diques, canales de riego y adecuadas obras de defensa que se vieron como indispensables desde los primeros años del territorio.

Empero, y durante la última mitad del siglo XIX, el Estado nacional limitó su accionar a las obras de infraestructura mínimas de menor costo y envergadura pero facilitó la inversión de capitales extranjeros de origen inglés en la zona norte del territorio, en la que se instaló el ferrocarril que unió Bahía Blanca con Neuquén y se realizaron las obras 
de irrigación indispensables para poner en producción las tierras del llamado "alto valle" del río Negro, ${ }_{1}^{11}$ quedando postergadas en su crecimiento las restantes zonas del territorio.

Esta situación, que resultó inmodificable durante la vigencia del orden conservador (1880-1916), aparecía como de pronta reversión con la llegada de la Unión Cívica Radical al gobierno nacional en 1916 y sus promesas de reparación económica para los territorios nacionales. Veamos a continuación cuáles eran los factores que impedían un desarrollo agrícola pleno en Río Negro.

La incorporación tardía de la Patagonia al mercado nacional implicó orientarla hacia dos actividades de alta rentabilidad: la compra y venta de grandes extensiones de tierra, facilitada por la liberalidad estatal y las actividades ganaderas extensivas, fundamentalmente ovinas (Girbal, 1976:18).

A partir de 1880, la necesidad de mejorar la calidad del ovino que se enviaba a los frigoríficos provocó el desplazamiento del Merino por el Lincoln, fenómeno observable en el sur de Córdoba y Entre Ríos y la mayor parte de la provincia de Buenos Aires. Se inició así un proceso de "desmerinización" que empujó a esta variedad hacia el sur del país, hacia los campos patagónicos (Barsky y Gelman, 2001:216 y ss).

Río Negro, al igual que sus vecinos Neuquén, Chubut y Santa Cruz, se identificó tempranamente con la actividad ganadera ovina abriendo un ciclo económico que se extendió hasta 1930 (Vapnarsky, 1983; Navarro Floria y Nicoletti, 2001:90). ${ }^{12}$

\footnotetext{
${ }^{11} \mathrm{Al}$ abordar la historia rionegrina, se consideró al eje fluvial del río Negro como vertebrador del espacio, distinguiéndose lo que se conoce hasta hoy como "alto valle", "valle medio" y "valle inferior" del río Negro. A esta división se agrega históricamente la zona cordillerana andina (oeste del territorio) y la llamada "línea sur", zona mesetaria y árida en el centro rionegrino. En líneas generales y siguiendo la división departamental de 1915, el alto valle comprende la zona norte del territorio y el valle inferior se ubica en la zona nordeste o también llamada "atlántica", sobre el océano del mismo nombre.

${ }^{12}$ La expansión ganadera conformaba un circuito productivo que involucraba al sur y al oeste de Río Negro. Por el sur, Chubut y Santa Cruz ingresaban ganado a través de Valcheta, punto neurálgico de las comunicaciones terrestres, y recibían ganado equino rionegrino; por el oeste el contacto era con Chile, comercio que se realizaba tanto en forma legal como clandestina aprovechando los numerosos boquetes abiertos en la cordillera y las dificultades de vigilancia efectiva de estos
} 
Mientras que la ganadería se expandía naturalmente favorecida por el incremento del merino de la pampa húmeda, el desarrollo de la agricultura rionegrina quedó condicionado a la necesidad de realizar obras de irrigación.

Para 1888 Río Negro cultivaba menos de la décima parte de su superficie apta para cultivo (Girbal, 1976:30). En el Censo Nacional de 1914 se consigna que se hallaban en producción 36276 hectáreas, de las cuales la mayoría correspondía a cereales (trigo y maíz), alfalfa y viñedos, con epicentro en el alto valle del río Negro (Censo Nacional de 1914:909). ${ }^{13}$ El Censo General de Territorios de 1920 registró un aumento en la superficie sembrada (42 606 hectáreas), pero la producción siguió concentrada en dos rubros: alfalfares en primer lugar (26 983 hectáreas) y cereales en segundo término con 12322 hectáreas (Censo de Territorios de 1920:172-175). Como se observa, la agricultura se abría paso lentamente en el territorio y con las obras necesarias la capacidad agrícola del territorio podría ampliarse considerablemente.

La inversión necesaria para poner en producción el valle inferior del río Negro requería una asignación considerable de fondos. Si bien se reconocía la importancia de estas obras, ${ }^{14}$ había que realizar una fuerte apuesta económica que no implicaba solamente decidir la construcción de canales. La cuestión se presentaba más compleja. Los condicionantes para esta actividad no se centraban exclusivamente en la falta de medios de comunicación baratos y rápidos ni en mercados exiguos. La producción podía colocarse en el vecino país de Chile, en el cercano territorio neuquino o chubutense o volcarse hacia los mercados consumidores más importantes de Bahía Blanca y Buenos Aires.

pasos. Inicialmente la actividad ovina se concentró en el departamento Adolfo Alsina, en el que estaba ubicada la capital del territorio (Viedma). Posteriormente el ovino se desplazó hacia la zona mesetaria, en la línea sur rionegrina.

${ }^{13}$ La extensión total del territorio correspondía a 206.750 km cuadrados de superficie, equivalentes a 65 mil hectáreas.

${ }^{14}$ Ya en 1888 Hilarión Furque, al realizar una Memoria descriptiva del Río Negro, estimaba que con obras de irrigación en el valle inferior se podrían poner en producción 70 mil hectáreas para agricultura en Viedma y Coronel Pringles. El Informe de Giosue Sironi (1903) era menos optimista: hablaba de 40 mil hectáreas de terreno apto para la agricultura en Viedma, San Javier y Cubanea. 
Si se pensaba encarar un desarrollo agrícola importante en el valle inferior había que mejorar la navegabilidad del río Negro, realizar obras de defensa contra las inundaciones ${ }^{15} \mathrm{y}$, fundamentalmente, solucionar el problema de la laguna El Juncal, verdadero mar de agua responsable de las inundaciones sufridas por la capital del territorio -Viedma- y su hinterland inmediato. Complementariamente, mejorar la vialidad y la instalación de vías férreas para comunicar los diferentes puntos comerciales del territorio facilitaría la rápida y barata salida de la producción rionegrina.

El imprevisible caudal del río impedía toda proyección futura de rendimientos en los cultivos y estimación de ganancias. Por eso, y a pesar de ser un territorio eminentemente fluvial, el agua constituyó un problema en Río Negro. Todo proyecto de desarrollo debía implicar necesariamente la solución de estas cuestiones fundamentales para el despegue agrícola del territorio. Pero la tendencia general señalaba hasta la primera década de 1910 la ausencia de propuestas de desarrollo orgánicas e integrales para el sur argentino. ${ }^{16}$

\section{El radicalismo en el gobierno y la cuestión agraria en los territorios}

Al cambiar el signo partidario del gobierno nacional se produjo una modificación en el estilo de hacer política sobredeterminado por el liderazgo carismático de Hipólito Yrigoyen. El radicalismo como

\footnotetext{
${ }^{15}$ Las crecientes del río Negro eran frecuentes y se registran desde la época colonial. En julio de 1899 una creciente de proporciones extraordinarias destruyó en forma completa las poblaciones ubicadas a lo largo del río obligando el traslado de la capital a Choele Choel y generando una áspera disputa acerca de la conveniencia de que Viedma, la localidad más afectada, continuara siendo la capital rionegrina. La economía rionegrina se vio duramente afectada, especialmente los incipientes cultivos de cereales que quedaron por largo tiempo bajo las aguas.

${ }^{16}$ La excepción la constituyó la Ley de Fomento de los Territorios Nacionales (1908) de autoría de Ezequiel Ramos Mexía, ministro de Agricultura (1906-1907) y Obras Públicas de la Nación (1907-1913). El plan contemplaba la valorización de las tierras en forma previa a su venta a través de la radicación de vías ferroviarias y un plan ambicioso de construcción de muelles, depósitos de carga y descarga, navegación de los ríos y canales de irrigación. Pero los trabajos autorizados por la ley de fomento se hicieron con lentitud y los ferrocarriles proyectados quedaron paralizados en 1913.
} 
movimiento nacional-popular se autoerigía como un colectivo totalizador y encarnación absoluta de la nación, cuya misión fundamental era incluir a la sociedad dentro de esta concepción mediante una política reparadora. En ese marco, los territorios nacionales fueron incluidos dentro de la necesaria renovación de las fuerzas productoras del país.

El presidente Yrigoyen expresó que al asumir el gobierno, los territorios se hallaban en un estado de virtual abandono. En el discurso oficial apareció reiteradamente la idea de impulsar su progreso como parte de la tarea emprendida por el nuevo gobierno (Diario de Sesiones, Senado Nacional, 1919-I:10-11; 1922:81).

En 1916 incorporar los territorios significaba en primer lugar tomar conocimiento de sus necesidades materiales, para poder dar respuesta más específicas, abandonando la uniformidad imperante hasta entonces. Como tarea primordial el gobierno se planteó garantizar la vida y seguridad de sus habitantes como condición sine qua non para impulsar el crecimiento económico y atraer a los inmigrantes. Las disposiciones que ordenaban un censo general de los territorios (1920) y la creación de diez cuerpos de gendarmería (1921) resultaron acordes con ambos postulados (Diario de Sesiones, Senado Nacional, 1920:9-10).

Dentro de ese esquema reparador el agro adquirió un papel fundamental. Para Yrigoyen la riqueza agraria constituía la base de la estabilidad económica del país. El Ministerio de Agricultura, hasta entonces una oficina netamente burocrática, debería convertirse en un organismo de mayor protagonismo, tutelar y consejero de los colonos y también impulsor del desarrollo agrícola y la incorporación de zonas aún inexploradas. ${ }^{17}$ En ese marco, y acompañando el renovado impulso de la producción agrícola a partir de la primera posguerra, ${ }^{18}$ el gobier-

\footnotetext{
${ }^{17}$ Sin embargo, el presupuesto del Ministerio de Agricultura entre 1916 y 1922 fue poco relevante y no alcanzaba a cubrir las necesidades básicas de las diferentes divisiones agrícolas.

${ }^{18}$ Durante la Primera Guerra Mundial (1914-1918), la ganadería argentina había sido beneficiada con el aumento en el precio de las carnes y la demanda internacional. La alfalfa había ocupado un lugar preponderante entre los cultivos. Esta tendencia se invirtió debido a la crisis ganadera de 1921: la alfalfa retrocedió y se registró un notable incremento en el área sembrada fundamentalmente de cereales y lino.
} 
no envió al Congreso un proyecto de colonización agrícola y ganadera, exponente fundamental de la orientación impresa al problema agrario, pero que no llegó a obtener sanción parlamentaria. ${ }^{19}$

Al ver frustradas las expectativas de reformulación del sistema agrario, el radicalismo propuso una revisión en la adjudicación de la tierra fiscal, medida que no comprometía seriamente los intereses de la burguesía representados en el partido y en el gobierno.

La mayor parte de esta tierra se hallaba concentrada en los territorios nacionales del sur. En 1918, el presidente Yrigoyen afirmaba que la revisión de la tierra fiscal constituía una verdadera obra de reparación con fuerte sesgo moralizador destinada a corregir rémoras del régimen anterior y a eliminar irregularidades subsistentes por largo tiempo. En el mensaje al Congreso de 1918 afirmaba lo siguiente:

Persiguese el fin de preparar y abrir los territorios a las nuevas corrientes de población, incorporándolos en forma legal al trabajo y a la civilización del país, y ese pensamiento ha de ser una de las preocupaciones preferentes del gobierno por la gran significación que le atribuye como factor del progreso nacional (Diario de Sesiones, Senado Nacional, 1918:12-13). ${ }^{20}$

Con este fin, el gobierno creó Oficinas de Tierras en cada territorio con el doble propósito de estimular la agricultura y vigilar el cumplimiento de los contratos. Paralelamente, se abocó a la revisión de las concesiones fiscales para establecer el estado actual de las adjudicaciones y considerar una eventual retroversión al Estado en el caso de comprobarse la falta de productividad de las mismas por abandono o incumplimiento de las concesiones. Una vez regularizado el dominio fiscal o realizadas las obras de irrigación, el Estado entregaría la tierra

\footnotetext{
${ }^{19} \mathrm{El}$ proyecto oficial de colonización agrícola y ganadera presentado en 1916 y reiterado en 1919, 1927 y 1929, buscaba radicar al colono a través de la creación de pequeñas granjas como una manera de descomprimir la cuestión agraria y atenuar los conflictos rurales. La única norma agraria de importancia aprobada fue la llamada Ley del Hogar de 1917, que dispuso la entrega de la tierra pública a los agricultores.

${ }^{20}$ Ver las repercusiones periodísticas en "La investigación sobre tierras. Actualidad", La Prensa, Buenos Aires, 17 de abril de 1917, p. 9, col. 5-6.
} 
en forma fraccionada para la colonización pastoril, agrícola o explotación forestal (Diario de Sesiones, Senado Nacional, 1920I:15). ${ }^{21}$

Este proceso resultó trunco en la medida que los sectores dominantes operaron para poner límites al reformismo del gobierno, aprovechando los estrechos contactos entre los sectores terratenientes y gran parte de la dirigencia política del radicalismo. No existió una clara voluntad política de reformar el sistema legal de la tierra pública ni de subsanar la precariedad del ocupante, que se hallaba a merced de las grandes firmas ganaderas o comerciales, verdaderas acaparadoras de tierras en el sur (Girbal, 1991:237-238). Por otra parte, la situación del agro se complicó entre 1916 y 1921, con una pérdida parcial de las cosechas y la emergencia de conflictos rurales, fundamentalmente en la región pampeana. Diversas razones vinculadas con grandes lluvias, la plaga de la langosta, la caída de los precios agrícolas a nivel mundial y el aumento de los costos de producción internos, agravadas por problemas en la comercialización y la falta de crédito agrario, conforman un complejo panorama que evidentemente afectó al sector más vulnerable del sistema -el arrendatario- y a las finanzas del Estado nacional sostenidas en gran medida por el comercio exterior de cereales.

Al iniciar Marcelo T. de Alvear su periodo presidencial (1922-1928), se reorganizó el Ministerio de Agricultura y se retomaron las propuestas sobre colonización agraria con mayor protagonismo estatal y sobre tierras privadas. Pero para los territorios el desarrollo agrario quedó condicionado a la concreción de obras públicas y a la creación de un fondo permanente para obras de fomento, iniciativas escasamente concretadas (Memoria del Ministerio del Interior 1926, III:2-3).

Al asumir Hipólito Yrigoyen su segundo periodo (1928-1930) el agro estaba en dificultades debido a la baja internacional en los precios de los cereales agravados en el orden interno por una persistente sequía. En líneas generales, si bien Yrigoyen intentó efectivizar programas en beneficio del agro y de los agricultores, no innovó sustancialmente en la política agraria (Solberg, 1975:278).

${ }^{21}$ En 1917 el gobierno reservó tierras entre los ríos Limay y Neuquén para irrigación y posterior fraccionamiento y entrega de la tierra para colonización. Ver también República Argentina, Boletín Oficial de la Nación, año XXV, Boletín No 6929 , marzo-abril de 1917, 1 de marzo de 1917, p. 8. 


\section{El problema del agua en Río Negro y los intereses estatales}

Desde la época colonial la cuestión de las inundaciones y las dificultades para la navegación del río Negro fueron problemáticas centrales en la vida de los habitantes rionegrinos. El único río navegable era el río Negro. Para surcarlo con embarcaciones se necesitaban barcos potentes y fácilmente maniobrables por la rapidez del descenso y las angosturas del río. La barra del río requería además que los buques fueran de poco calado aunque esto se podía atenuar con la colocación de remolcadores. A su vez las crecientes dejaban en superficie la flotación de árboles y raigones que operaban fijando el pedregullo y la arena formando los desplayaderos, verdaderos obstáculos para la navegación.

Desde tiempo atrás se venían practicando estudios para mejorar la navegación, sin ponerse en práctica ninguna de las propuestas. En 1917 se dispusieron nuevos estudios para la navegabilidad tanto de los ríos Negro como Neuquén y en 1920 una comisión técnica realizó estudios para habilitar el canal de acceso al puerto de Patagones. Sin embargo los fondos no aparecían. En 1920 el gobernador interino de Río Negro Carlos Evrat (1916-1920) propuso la utilización de deslizadores para mejorar la navegabilidad entre Neuquén y Viedma. ${ }^{22}$ La Inspección General de Navegación y Puertos Marítimos objetó la propuesta alegando no sólo el tema de los vientos que podían afectar la capacidad de maniobra sino fundamentalmente la escasa capacidad de carga de los deslizadores, inferior al volumen de productos que se transportaban por el río Negro, lo que haría oneroso el comercio. Expresaba que "el problema a resolver en el río Negro no consiste en el transporte rápido de las personas sino en el transporte económico de las cosas" (Informe Ministerio de Obras Públicas de la Nación, 1919).

La Inspección de Navegación no estaba tan equivocada. La navegabilidad por sí sola no bastaba para agilizar el comercio. Lo que se requería era una mayor infraestructura para carga y descarga de los productos. A 36 años de creado el territorio, su capital Viedma

22 “Línea férrea a Patagones," La Nación, Buenos Aires, 16 de junio de 1920, p. 4, col. 1-2. 
carecía aún de un muelle nacional y debía valerse del de Patagones ${ }^{23}$ para recibir y enviar la producción. Los productos desde y hacia Viedma se embarcaban y desembarcaban allí ocasionando demoras en su retiro y envío con el consiguiente aumento de precios al ser trasladados en chatas remolcadas por lanchas a nafta. En 1916 el muelle de Viedma estaba en construcción y ya el Ministerio del Interior preveía que iba a resultar insuficiente y que debía completarse con un muelle de mayor envergadura que en 1920 aún estaba en construcción.

Por otra parte, la navegación de cabotaje entre Viedma y Roca se hallaba interrumpida desde 1914, con el consiguiente perjuicio para el comercio. En 1926 el gobernador de Río Negro León Quaglia (19261929) aún reclamaba la ejecución de las obras de dragado, balizamiento, adquisición de embarcaciones y navegación del río Negro (Memoria de la Gobernación de Río Negro, 1926).

A los inconvenientes provocados por las dificultades en la navegación y la carga y descarga de los productos, debemos sumarle la necesidad de obras de defensa e irrigación tanto para el valle medio como para el valle inferior del río Negro. A finales de 1915 un desborde extraordinario del lago Currilauquen sobre el río Colorado arrasó con la población, los cultivos y el ganado desde Catriel -límite con el territorio de La Pampa- hasta río Colorado en el valle medio. En General Conesa, localidad situada a 158 kilómetros de Viedma río arriba, la situación era sumamente difícil ya que las creciente había alcanzado los cuatro metros, se había desmoronado la ribera, destruido casas particulares y era imperioso desviar el antiguo cauce del río. En 1916 se diseñó un proyecto que resultó impracticable y en 1924 la Dirección General de Irrigación realizó una nueva propuesta que consistía en la construcción de un dique insumergible. Para 1933 los vecinos aún reclamaban por obras de defensa que el Ministerio de Obras Públicas consideró necesario replantear (Boletín Oficial de la Gobernación de Río Negro, 1926). Evidentemente los tiempos de la burocracia eran lentos

\footnotetext{
${ }^{23}$ Carmen de Patagones constituye la localidad más austral de la provincia de Buenos Aires. Fundada en 1779, se encuentra separada del territorio rionegrino por el río del mismo nombre.
} 
incluso frente a situaciones que implicaban la pérdida de vidas, ganado, cultivo y propiedades.

La irrigación era una necesidad innegable pero el gobierno había dilatado sin demasiados argumentos las obras en el valle medio e inferior del río Negro. Durante los primeros años de gobierno radical se aprobaron y ejecutaron sucesivas propuestas vinculadas con el riego en el río Negro Superior; pero en el resto del territorio las obras de irrigación sufrieron sucesivas postergaciones. Ante la dilación los vecinos, imitando la modalidad adoptada en el alto valle, ${ }^{24}$ decidieron constituir cooperativas para realizar los canales. En 1920 la Dirección de Irrigación debió hacerse cargo de los canales construidos por particulares en el valle medio, pero el funcionamiento del riego era deficiente. En 1928 se aprobó el proyecto y presupuesto para obras de riego y en 1929 una disposición similar favoreció a la localidad de Lamarque (Boletín Oficial de la Gobernación de Río Negro, 1928:6-7).

Hay un aspecto importante a destacar. Se alentó la construcción de canales y el aprovechamiento del agua ya que éstos constituían una fuente de ingresos para el gobierno que percibía el canon correspondiente. Los gobernadores quedaron imposibilitados de realizar concesiones para la utilización de las aguas de ríos y arroyos dentro del territorio a pesar de las disposiciones del Código Rural. En 1915 la Dirección de Irrigación del Ministerio de Obras Públicas absorbió esta facultad y nombró delegados en los territorios (Boletín Oficial de la $\mathrm{Na}$ ción, 1915:180) y en 1919 se reglamentaron las funciones del cobrador fiscal para la percepción del canon de riego. ${ }^{25}$

En las zonas donde no se habían construido canales, también se reglamentó el uso del agua. A partir de 1918 la Dirección de Irrigación

\footnotetext{
${ }^{24}$ Las Cooperativas de Irrigación fueron una forma de organización predominante en el alto valle a partir de principios del siglo Xx: la Cooperativa de Irrigación de General Roca en 1907, la de Choele Choel en 1909, la de Colonia Cervantes en 1910 y la Cooperativa del Este de la colonia Roca en 1912.

${ }^{25}$ El canon de riego quedó establecido a partir de la ley de irrigación de 1909, que incluía un plan de irrigación para los ríos Negro, Neuquén y Colorado. Era anual y se formaba sumando los gastos de las obras (incluye los estudios previos), el servicio anual por interés y amortización, el costo del mantenimiento y el gasto de la administración del riego. Ese total se dividía por la cantidad total de hectáreas a regar, dando un valor fijo por hectárea.
} 
asumió un papel más contundente y dispuso sucesivas inspecciones de las concesiones de agua realizadas por los gobernadores.

Evidentemente la renta del agua es un aspecto a considerar que implica la ampliación del aparato burocrático y una nueva fuente de ingresos que es necesario cuantificar a la vez que determinar la efectividad de la modalidad adoptada para la concesión del uso del agua para riego.

\section{El valle inferior y el problema de la laguna El Juncal}

De todas las zonas del territorio rionegrino, el valle de Viedma era el que presentaba una situación más compleja. No sólo porque el río arrasaba con poblaciones y cultivos sino porque la situación se veía agravada por la presencia inquietante y amenazante de la laguna El Juncal. ${ }^{26}$

Esta inmensa masa de agua obraba como bisagra para cualquier intento de crecimiento económico basado en la producción agrícola. La laguna se hallaba sujeta al régimen del río Negro, razón por la que una creciente de este río inmediatamente duplicaba el volumen de agua que circulaba por los zanjones ocasionando su inmediato desborde. El valle se convertía entonces en una cuenca de agua sin salida exterior. Al bajar la creciente parte del agua permanecía estancada y no llegaba a evaporarse, convirtiendo a la laguna en parte del paisaje cotidiano de Viedma.

De esta manera Viedma y su zona de influencia quedaban aisladas. El ejido urbano de Viedma era apto para vivir solamente hasta la sexta manzana; más allá la laguna impedía todo asentamiento permanente (Libros de Inspecciones de Tierras 1919 y 1920, II:339). Las explotaciones agropecuarias sufrían severos daños, especialmente los campos para pastoreo que quedaban inutilizados y cuyas haciendas

\footnotetext{
${ }^{26}$ Esta laguna se extendía en forma paralela al curso del río y en una longitud que rondaba los 60 kilómetros, con una amplitud de hasta 4 mil metros y abarcando, en épocas de bajante del río, una superficie estimada en 15430 hectáreas. Su avance inutilizó por largo tiempo dos tercios del ejido de Viedma. Se alimentaba de seis zanjones que llevaban los apellidos de los primigenios propietarios de tierras. Con el río en creciente, su superficie abarcaba 40 mil hectáreas.
} 
debían ser trasladadas en forma permanente. Del mismo modo, resultaba imposible transitar por la costa de la laguna y para cruzarla había que dar un largo rodeo, lo que afectaba a las personas pero también a las tropas de carros que traían productos para comerciar que obviamente se encarecían por las demoras, las dificultades del acarreo, el aumento en el valor del flete y el consiguiente deterioro de la producción. La presión fiscal oprimía a los pobladores que debían seguir pagando altos impuestos por propiedades inundadas, contando en algunas ocasiones con prórrogas otorgadas cuando las pérdidas eran considerables. ${ }^{27}$

Hasta la llegada del gobierno radical no se habían encarado más que obras de escaso impacto para aliviar la situación provocada por la laguna: un puente de madera construido durante la gobernación de Napoleón Berreaute (1888-1892) y defensas precarias levantadas por los vecinos. Restaba aún construir puentes y terraplenes y obras de envergadura como la desecación de la laguna. A pesar de existir proyectos ya aprobados -como el del agrimensor Ernesto Gramondo en 1899-, no hubo decisión política para encarar las obras.

El Estado debía asumir aquí un papel preponderante ya que los escasos fondos asignados a la gobernación sólo alcanzaban para reparaciones menores. Sin embargo, en 1919 el gobierno nacional reconocía que la irrigación no estaba entre sus prioridades y que los fondos destinados a ella eran limitados (Diario de Sesiones, Senado Nacional, 1919, I:10).

En 1921 el presidente de la comisión de la laguna El Juncal expresaba que

[...] el problema de la laguna El Juncal es un asunto que interesa vivamente a esta población. Es un asunto que se viene debatiendo hace años, sin llegar a una finalidad práctica, a

\footnotetext{
${ }^{27}$ Los propietarios de los territorios abonaban el impuesto de contribución territorial sobre bienes raíces particulares. Este impuesto era recaudado dentro del ejido por el Concejo Municipal y fuera de él por la Subcolecturía de Rentas Nacionales, con delegaciones en Viedma, Bariloche y San Antonio Oeste. Los pobladores que tenían haciendas en tierras fiscales abonaban un derecho de pastaje anual por cabeza de ganado, reglamentado en 1915 y recaudado por la Comisión Inspectora de Tierras a través de las oficinas recaudadoras en diversas localidades del territorio.
} 
una realidad tangible. La comunicación entre Viedma y su campaña es de tan imprescindible necesidad que no han faltado esfuerzos meritorios de esta población para que al par de librarla del peligro que constantemente la amenaza, hiciera factible su comunicación en condiciones de bondad, economía y rapidez. Pero los esfuerzos, señor gobernador, han tenido que estrellarse ante las dificultades de orden económico, imposibles de salvarlas la mejor buena voluntad de la población, dada la magnitud de la obra que era necesario realizar (Expediente Administración de Gobierno, VI, 1920).

Evidentemente se requería una decisión que pusiera en marcha las obras. Por largo tiempo la modalidad adoptada por el gobierno nacional había sido la realización de estudios técnicos a cargo de profesionales -agrónomos e ingenieros- de las oficinas ministeriales. Éstos se trasladaban al lugar, elaboraban un plan y a veces llegaban a presentar un presupuesto. La realización de estudios era rentada y generalmente los estudios y su presupuesto resultaban aprobados pero no se ejecutaban. ${ }^{28}$ Otra forma habitual utilizada por las oficinas ministeriales era alegar que el presupuesto era insuficiente y solicitar un aumento que demoraba en ser tratado y aprobado. Pasado un breve lapso de un año o dos se decidía iniciar de nuevo la consulta con otro profesional, que podía integrar o no el elenco burocrático, al que se le encargaba nuevamente la realización de estudios -sin tener en cuenta los ya efectuados- y que elaboraba una nueva propuesta. En ocasiones se finalizaba el proceso de estudios, presupuesto y aprobación, se consignaba y reservaba la partida pero los fondos no llegaban al territorio, a pesar de los reclamos al respecto.

Estas estrategias dilatorias constituían una modalidad de antigua data que encubría una manera eficaz de ampliación del aparato buro-

\footnotetext{
${ }^{28}$ A modo de ejemplo, en 1889 se habían realizado los primeros estudios para la irrigación de cinco departamentos rionegrinos. En 1892 el gobierno nacional firmó un contrato con el agrimensor Guillermo Estrella para un canal de irrigación en la costa sur del río Negro, que nunca se ejecutó. En 1900 y 1901 se realizaron estudios para evitar inundaciones del río Negro. En 1911, el ingeniero Ramón Quartino presentó un proyecto que aspiraba regar 70 mil hectáreas y utilizar la laguna El Juncal como área de drenaje, pero ese proyecto recién fue aprobado en 1930. En 1914 se solicitó otro proyecto similar a Humberto Poggi, también sin resolución.
} 
crático estatal, a través de la contratación sucesiva de profesionales que rotaban por los territorios nacionales efectuando estudios de similar tenor. Por otra parte, el anuncio de nuevos estudios, ampliamente difundidos por la prensa regional y nacional, servía para mostrar al gobierno como activo e interesado en la problemática territorial. Sea cual fuere la motivación, la resultante eran obras anunciadas pero inconclusas, ya sea porque los fondos se utilizaban para otros fines o porque las mismas no estaban dentro de las prioridades gubernativas.

El radicalismo no se alejó de esta modalidad durante su gestión. En 1917 el gobierno envió un técnico de la Dirección de Puentes y Caminos -el ingeniero Abel Cornejo- para que estudiara la apertura de un camino de acceso a Viedma sobre el paso grande de la laguna. Dos años más tarde un nuevo estudio técnico, esta vez a cargo del ingeniero Carlos Alonso, verificó las condiciones para la construcción de un puente. En 1920 se había aprobado el presupuesto y la obra sería realizada con fondos estatales con el concurso financiero de los vecinos del valle inferior y de la gobernación, que debía poner a disposición elementos y útiles para las obras y encargarse de custodiar la terminación de los trabajos y su posterior conservación. La gobernación accedió a estos requerimientos pero entre 1925 y 1927 tres decretos sucesivos fueron modificando el presupuesto para el estudio de las obras de riego en General Conesa y Frías. En 1930 el gobierno nacional preparó un nuevo plan para obras de riego en Conesa y Frías que beneficiaba a 19 mil hectáreas. Este plan quedó sin realizar por la decisión del gobierno de facto (1930-1932) de suspender toda obra sin ejecutar. En 1933 aún se reclamaban las obras de defensa para Conesa.

En el caso de Viedma, en 1925 se dispuso la licitación de obras de defensa costera pero la Dirección de Irrigación solicitó una postergación para introducir modificaciones al proyecto que obviamente aumentaron el presupuesto inicial. En 1927 se aprobó el contrato con Pedro Figliozzi para la construcción de un terraplén de 80 km de largo, revestimiento de hormigón y tablestacado de madera dura. Aparentemente este terraplén no quedó bien construido ya que las inundaciones de junio y agosto de 1930 destruyeron varias partes del mismo. 


\section{Las áreas de interés. Acciones estatales mínimas para Río Negro}

Si la solución de los problemas básicos que impedían desarrollar la agricultura constituyó una asignatura pendiente, resulta válido preguntarnos sobre qué aspectos el Estado concentró su actividad y cuáles fueron las obras que el gobierno realizó en el territorio nacional de Río Negro.

Podemos afirmar que en líneas generales la acción del gobierno radical sobre Río Negro respondió a los cánones básicos de la etapa precedente. No se realizaron grandes inversiones en obras públicas que facilitaran el desarrollo agrícola pero se garantizaron las necesidades mínimas para el comercio y la circulación de personas y bienes en el territorio. La mayor parte de las medidas tomadas entre 1916 y 1930 se vincularon con la construcción y reparación de caminos, puentes sobre arroyos y ríos, terraplenes, zanjas y desagües, y en menor medida con la terminación de edificios públicos y líneas de telégrafos.

Esta tendencia ya había sido anticipada al iniciarse el gobierno radical. En una declamación discursiva que revelaba que las necesidades mínimas de los territorios aún no estaban cubiertas, se afirmaba que

[...] el porvenir de los territorios nacionales depende en gran parte de las obras públicas que en ellos se realicen y especialmente en la vialidad. No puede haber población, comercio e industrias sin puentes, caminos y medios de transporte, sin correos, telégrafos; no puede haber administración normal sin edificios apropiados, seguridad publica sin cárceles, higiene sin agua corriente (Memoria Ministerio del Interior, 1916:39).

En 1922, al asumir el presidente Marcelo T. De Alvear se expresó en similares términos, afirmando la necesidad de proyectar medidas para el "engrandecimiento material de los territorios" y ampliar las partidas destinadas a vialidad y edificios públicos (Memoria del Ministerio del Interior, 1922:259-260).

En función de estas afirmaciones el tema de las comunicaciones recibió atención preferente. Los caminos del territorio requerían reparaciones permanentes y nuevos trazados. Desde 1914 existía una cuadrilla de peones camineros encargados de conservar los terraplenes, 
construir zanjas, reparar y conservar los caminos y realizar los desagües. En 1926, al crearse la policía rural, se incluyó dentro de sus funciones la conservación de los caminos del territorio. ${ }^{29}$

El servicio de balsas indispensable para remontar el río fue otorgado mediante concesiones a particulares o sociedades, previa verificación del servicio por la Dirección de Puentes y Caminos.

La gobernación realizó diferentes gestiones y acompañó las iniciativas con comentarios a veces no exentos de críticas. En 1928 el gobernador León Quaglia, al redactar su Memoria, expresaba que

[...] las obras públicas realizadas o recientemente iniciadas en este territorio por el gobierno nacional, han llenado sentidas necesidades, con excepción lamentable del edificio levantado en la pequeña población de Lamarque para asiento de las oficinas de Correo, Comisaría y Juzgado de Paz [...] el mencionado edificio no tiene razón de ser, dado que para una población tan reducida resulta hasta grotesco el espectáculo de una obra tan amplia que carece de objetivo práctico alguno. Considero una medida inconsulta, que no beneficia más que a determinados interesados [...] En cambio en esa misma localidad, como asimismo en las de Choele Choel y Luis Beltrán, juzgo necesario proceder de inmediato a la ejecución de los trabajos concernientes a irrigación (Memoria de la Gobernación de Río Negro, 1928:4).

El gobernador manifestaba claramente dónde radicaban las necesidades vitales del territorio centradas en la solución a los factores estructurales que trababan el desarrollo agrícola rionegrino.

La extensión de los ferrocarriles no fue completada en su totalidad a pesar de las gestiones de vecinos, gobernadores y diputados al respecto. Para Río Negro era fundamental terminar las obras proyectadas en 1908 y que se vinculaban con la construcción del ferrocarril de San Antonio Oeste al lago Nahuel Huapi. En 1916 esta construcción se hallaba paralizada y de sus $623 \mathrm{~km}$ iniciales sólo se habían realizado

${ }^{29}$ En Río Negro entre 1916 y 1930 el Estado construyó sólo cuatro caminos y arregló dos terraplenes y seis puentes. 
425. La construcción resultaba onerosa por las dificultades del terreno montañoso, lo que obligaba a construir terraplenes, puentes y alcantarillas. En 1917 el Ejecutivo elevó un proyecto para la finalización de las obras que incluía la sugerencia de la Dirección General de Territorios Nacionales de emplear en las obras a los presos de las cárceles del territorio. En 1922 se hallaban en construcción 192 kilómetros más de este ramal y en 1926 se dispuso que las vías llegaran hasta Bariloche ya que la construcción se hallaba detenida en Pilcaniyeu.

En cuanto a la cuestión de la tierra pública, las medidas tomadas por el gobierno afectaron la posibilidad de desarrollo del agro y retrasaron la entrega de la tierra fiscal que aún retenía el Estado, al generar dudas acerca de la validez de los títulos emitidos, sobre todo en el caso de las tierras otorgadas por los municipios.

Río Negro no había escapado a un sistema de tenencia de la tierra caracterizado no sólo por su liberalidad sino por la incongruencia y falta de unificación de muchas de sus disposiciones, leyes y decretos. Río Negro fue un territorio que a diferencia del conjunto patagónico fue objeto tempranamente de normativas vinculadas con la distribución y el usufructo de la tierra pública. No sólo porque en su margen sur fueron aplicados los decretos y las leyes de la provincia de Buenos Aires a partir de 1821,30 sino porque desde la penetración militar del Estado nacional en 1878, la zona de antiguo poblamiento fue la inicialmente escogida para financiar con la tierra la campaña militar y la instalación de la Gobernación de la Patagonia (1878-1884).

El gobierno nacional enajenó la tierra en la zona de más antiguo poblamiento del territorio: el valle inferior. A partir de ese momento una profusa y confusa legislación superponía diferentes modalida-

30 Toda la Patagonia quedó bajo la soberanía de la provincia de Buenos Aires a partir de su creación en 1820. Si bien la constitución provincial de 1854 estipulaba que los límites bonaerenses abarcaban hasta el Cabo de Hornos, esta soberanía se ejerció en forma efectiva hasta la margen sur del río Negro, en el lugar en que posteriormente se ubicó la localidad de Viedma, capital del territorio. Esta zona se benefició con el decreto de entrega de la tierra de 1821, la ley provincial de 1855 y las entregas de tierras a particulares efectuadas a partir de 1863, normativas que disponían la donación gratuita de la tierra y que fueron reconocidas por el gobierno nacional a partir de la aplicación de la ley de derechos posesorios número 1552 de 1884 . 
des de acceso a la tierra: colonias oficiales y particulares, ${ }^{31}$ arrendamiento de grandes extensiones, venta, premios en tierras como reconocimiento de acciones militares, suscripción de un empréstito y reconocimiento de derechos a antiguos ocupantes. Con posterioridad a 1884 se ofrecieron en forma fraccionada lotes en la zona del alto y medio valle del río Negro y ya en las primeras décadas del siglo XX se completó la entrega de la tierra en la zona cercana al puerto de San Antonio, la zona andina y mesetaria. El proceso fue lento: hacia finales del siglo XIX, de los 19669500 hectáreas de tierra que tenía Río Negro, 70\% continuaba siendo fiscal y sólo 30\% se hallaba en manos particulares (Memoria del Ministerio del Interior, 1899:67).

A diferencia de la zona norte del territorio, los que habían tenido acceso al dominio de la tierra eran ocupantes locales, observándose escaso interés de capitalistas de la pampa húmeda por las tierras del valle inferior. Obviamente las dificultades con las crecientes y la falta de irrigación de las tierras desalentaron inversiones en el valle de Viedma. Los antiguos pobladores del territorio, instalados en las tierras desde la segunda mitad del siglo XX y convertidos en sectores dominantes locales, fueron los que ocuparon la mayoría de las tierras disponibles, cooptaron el municipio y juzgado de paz local ${ }^{32} \mathrm{y}$ fueron partícipes activos de las gestiones en pos de las obras indispensables para el desarrollo agrícola (Ruffini, 2008).

Río Negro fue incluido en la investigación practicada sobre tierras durante el gobierno radical. Pero para 1921 aún no se había efectivizado la inspección y muchos expedientes se hallaban paralizados, lo que había dado lugar a la especulación denunciada por el interventor de la Dirección de Tierras Isidro Maza (Boletín Oficial de la Gobernación de

\footnotetext{
${ }^{31}$ Nos referimos a las colonias Conesa y Frías (1879), la colonia Valcheta (1889) y la llegada de alemanes a General Roca (1885) y de galeses a la isla de Choele Choel (1902).

${ }^{32}$ Como ya mencionamos, la ley de territorios nacionales de 1884 establecía que los únicos derechos políticos que podían ejercer sus habitantes era la elección de municipio y juzgado de paz, en localidades que superaran los mil habitantes. En Río Negro esta condición electiva fue adquirida tempranamente por Viedma y Coronel Pringles (1886), seguidas por General Roca (1889), Río Colorado (1902), San Antonio (1912) y Allen en 1916.
} 
Río Negro, 1921:4-5). Por resolución ministerial de 1919 se había dispuesto que mientras se realizaran las inspecciones no se modificara la situación de la tierra fiscal ni se concedieran nuevos títulos.

Otra cuestión conflictiva era la venta de tierra dentro del ejido municipal. Esa facultad había sido otorgada a los municipios electivos por la ley de 1884 y su modificatoria de 1890, para ser retirada por la ley de tierras de 1903, con la salvedad del reconocimiento expreso de los títulos otorgados antes de esa fecha. En diciembre de 1907 se reglamentó esta disposición, medida que fue ratificada en 1912, 1916 y 1922. La cuestión a elucidar era la situación de los títulos emitidos entre la fecha de sanción de la ley y su efectiva reglamentación.

El gobierno radical debió abordar esta cuestión que no sólo era vital para los que tenían títulos sobre las tierras sino para la misma municipalidad -que percibía $40 \%$ de las rentas- y para las oficinas nacionales, que debían ocuparse de estos trámites que resultaban largos y dificultosos. En 1928 se ratificó el espíritu de la normativa de 1903 reconociendo la validez de los títulos emitidos con anterioridad a esa ley. Los casos posteriores serían ponderados en particular.

Pero la lenta maquinaria burocrática nuevamente operó con dificultades: para 1930 aún no se había dictaminado sobre los casos pendientes de tierras fiscales otorgadas por los municipios.

Esta situación aporta otros elementos para la comprensión de la política agraria. Muchas iniciativas y propuestas quedaron truncas por la inoperancia de un sistema poco consolidado y con diferencias de criterio y opinión en sus oficinas. La dispersión de los asuntos económicos de los territorios en tres carteras -Interior, Obras Públicas y Agricultura- con sus respectivas oficinas atentaron contra la unidad de principios y contra la eficacia y rapidez en la resolución de las cuestiones básicas vinculadas con el desarrollo de los territorios.

Del mismo modo, la ausencia de sectores de la burguesía nacional en el valle inferior del río Negro implicó la irresolución de cuestiones pendientes que afectaron el dominio pleno de la tierra pública y quizá desalentaron la posibilidad de inversiones de mayor envergadura. 


\section{A modo de conclusión}

El caso de los territorios nacionales como entidades centralizadas y funcionalmente dependientes del gobierno central nos permite observar en forma privilegiada el accionar del Estado en materia agraria. No sólo porque en ellos el Estado tenía el absoluto control sobre su presente y futuro sino porque el gobierno resguardó estos espacios como enclaves estatales en los que el poder del Estado podía operar libremente. Del mismo modo el aparato burocrático encontró allí una posibilidad de ramificación y penetración que resultó políticamente eficaz al permitir el ejercicio sostenido del clientelismo.

La mentada "reparación radical" no se tradujo en hechos concretos, desde el punto de vista económico, para los territorios. Al igual que en la faz política, la política agraria radical no implicó una ruptura total con el orden conservador. Los problemas que condicionaban y limitaban un crecimiento sostenido en Río Negro no fueron subsanados por el gobierno radical a pesar de la pretensión expresa de impulsar el progreso y desarrollo como una manera de diferenciarse de la etapa precedente. Sin embargo, en materia de política agraria se puede trazar una clara línea de continuidad con ese orden que se presentía reparar y superar. Se puede decir que los territorios fueron objeto de acciones diferenciadas que resultaban coherentes con los intereses de la clase dominante nacional, al sostener el latifundio, los intereses de las grandes firmas y las inversiones selectivas sin promover la integración y articulación al modelo económico de las zonas marginales o postergadas.

En Río Negro, el radicalismo se centró en consolidar económicamente el alto valle del río Negro, reforzando la presencia del capital extranjero y aprovechando la infraestructura existente que fue ampliada y perfeccionada y que posibilitó el desarrollo de la fruticultura y la vitivinicultura a partir de 1930, actividades donde se observa claramente la presencia de sectores dominantes de la burguesía nacional.

El interés por el desarrollo agrícola de Río Negro quedó entonces circunscrito a esta región donde esta actividad ya estaba presente aunque en forma incipiente. El resto de las zonas, y fundamentalmente el valle inferior, que era el que requería la mayor atención 
oficial, fue objeto de escasas acciones. Las obras realizadas se centraron en el mantenimiento de los caminos, completar las vías férreas y los aspectos menos complejos y onerosos del aprovechamiento de los ríos como la concesión y el mantenimiento de las balsas, así como el usufructo de la renta del agua, reglada y controlada de cerca por el gobierno.

Las estrategias desplegadas por el gobierno radical no difieren sustancialmente de la etapa anterior marcando un nuevo rasgo de continuidad: la recurrencia a estudios técnicos de prefactibilidad alimentaban una burocracia de funcionarios y otorgaban una apariencia de preocupación y acción del Estado, sin concretar las obras necesarias.

Si pensamos que los territorios habían sido creados en 1884, en un momento de expansión económica y desarrollo agropecuario, no era comprensible -aunque sí explicable- que aún permanecieran en los primeros estadios de inversión de obras públicas básicas e indispensables como telégrafos, caminos y edificios. Evidentemente la escasa acción del Estado había sido una constante y el radicalismo tampoco encaró una aceleración del proceso que permitiera comunicar, integrar y desarrollar el territorio.

Razones vinculadas con la crisis económica de la primera posguerra, las alteraciones del mercado externo en lo atinente al valor de los precios internacionales del agro y la ganadería y las inevitables y conocidas dificultades del radicalismo en su relación con el Congreso Nacional, resultan factores explicativos que podemos argüir en una interpretación de la política agraria para los territorios, política que evidentemente no puede separarse de la modalidad adoptada por el radicalismo en esta materia a nivel nacional.

Esta dilación en la solución de cuestiones estructurales básicas podría deberse, en primer lugar, a que la inversión estatal era importante y por ello fue postergada deliberadamente a través de la figura de estudios técnicos y de factibilidad; pero también habría que considerar la ausencia -a diferencia de la zona norte del territorio- de un sector dominante local con ramificaciones y vinculaciones con la clase dominante nacional, circunstancia que obró como límite efectivo para operar eficazmente sobre el Estado y motivar respuestas más contundentes. 


\section{Bibliografía}

Fuentes primarias

Archivo Histórico Provincial de Viedma, Boletín Oficial de la Gobernación del Río Negro 1916-1930 (varios volúmenes).

Archivo Histórico Provincial de Viedma, Sección Administración de Gobierno. 1916-1930, Documentos y Expedientes Oficiales y de Particulares (varias cajas).

Archivo Histórico Provincial de Viedma, Gobernación de Río Negro, Memoria de la Gobernación de Río Negro elevada al Ministerio del Interior, años 1926 y 1928.

Congreso Nacional, Cámara de Diputados y de Senadores, Diario de Sesiones (1916-1930),Varios tomos.

La Nación, Buenos Aires, años 1917 y 1920.

La Prensa, años 1916-1919.

República Argentina, Tercer Censo Nacional levantado el $1^{0}$ de junio de 1914 y ordenado por ley No 9108 bajo la presidencia de Roque Sáenz Peña ejecutado durante la vicepresidencia de Victorino de La Plaza. Buenos Aires, Rosso, 1916, tomo VI, pp. 909,923 y 939.

República Argentina, Ministerio del Interior, Asesoría Letrada de los Territorios Nacionales, Censo General de Territorios Nacionales de 1920, tomo II, Neuquén, Río Negro, Chubut, Santa Cruz y Tierra del Fuego, Buenos Aires, Establecimientos Gráficos De Martino, 1923.

República Argentina, Ministerio del Interior, Memorias 1916-1930 (varios tomos).

Bibliografia

Astori, Danilo (1984), Controversias sobre el agro latinoamericano. Un análisis crítico, Buenos Aires, ClACSO.

Barsky, Osvaldo y Jorge Gelman (2001), Historia del agro argentino. Desde la Conquista hasta finales del siglo XX, Buenos Aires, Grijalbo.

Chiaramonte, José Carlos (1995), Ciudades, provincias, estados. Orígenes de la Nación Argentina (1800-1846), Buenos Aires, Ariel, Biblioteca del Pensamiento Argentino, tomo I. 
Girbal de Blacha, Noemí (1976) , “La agricultura rionegrina y su ingerencia en la economía patagónica y nacional, 1900-1913. Contribución al estudio de la historia regional", Universidad Nacional de La Plata, Facultad de Humanidades y Ciencias de la Educación, Departamento de Historia, Instituto de Historia Económica y Social Argentina y Americana, Historia. Investigaciones I, pp. 15-66.

(1991), “Política de tierras públicas en la Argentina (1916-1930). El caso de los territorios nacionales del sur," Revista de Historia del Derecho, núm. 19, Buenos Aires, separata, pp. 209-243.

Mandrini, Raúl, Antonio Ohmste de Escobar y Sara Ortelli (2007), Sociedades en movimiento. Los pueblos indígenas de América Latina en el siglo XIX, Tandil, Universidad Nacional del Centro, Instituto de Estudio Histórico-Sociales.

Mases, Enrique (2002), Estado y cuestión indígena. El destino final de los indios sometidos en el sur del territorio (1878-1910), Buenos Aires, Prometeo.

Navarro Floria, Pedro y María Andrea Nicoletti (2001), Río Negro, mil voces en una historia, Neuquén, Manuscritos.

Oszlak, Óscar (1990), La formación del Estado argentino, Buenos Aires, Editorial de Belgrano.

Quijada, Mónica (2002), “Repensando la frontera sur argentina: concepto, contenido, continuidades y discontinuidades de una realidad espacial y étnica (siglos XVIII y XIX)", Revista de Indias, vol. LXII, núm. 224, pp. 103-142.

Ratto, Silvia (2007), Indios y cristianos. Entre la guerra y la paz en las fronteras, Buenos Aires, Sudamericana.

Rey, Héctor et al. (1987), Historia del valle inferior del río Negro. El nuevo distrito federal, Buenos Aires, Plus Ultra.

y Luis Vidal (1974), Historia de Río Negro, Viedma, Comisión de Investigaciones Científicas y Gobierno de la Provincia de Río Negro.

Ruffini, Martha (2008), “Agro, política y sectores dominantes en el valle inferior del río Negro (siglo XIX hasta la década de 1940", en Javier Balsa, Graciela Mateo y María Silvia Ospital (comps.), Pasado y presente del agro argentino, Buenos Aires, Lumiere. 
Ruffini, Martha (2007), La pervivencia de la República posible en los territorios nacionales. Poder y ciudadanía en Río Negro, Bernal, Universidad Nacional de Quilmes, Serie Convergencia. Entre memoria y sociedad.

Solberg, Carl (1975) “Descontento rural y política agraria en la Argentina, 1912-1930", en Marcos Gimenez Zapiola, El régimen oligárquico. Materiales para el estudio de la realidad argentina hasta 1930, Buenos Aires, Amorrortu.

Toldo, Hugo Ángel (1980), Río Negro, pasado y presente, Buenos Aires, Chrismar.

Vapsnarsky, César (1983), Pueblos del norte de la Patagonia (1779-1957), General Roca, Ediciones de la Patagonia, Argentina.

Recibido en julio de 2008 Segunda versión recibida en diciembre de 2008 Aceptado en enero de 2009 
Mapa 1. Los territorios nacionales argentinos en 1930

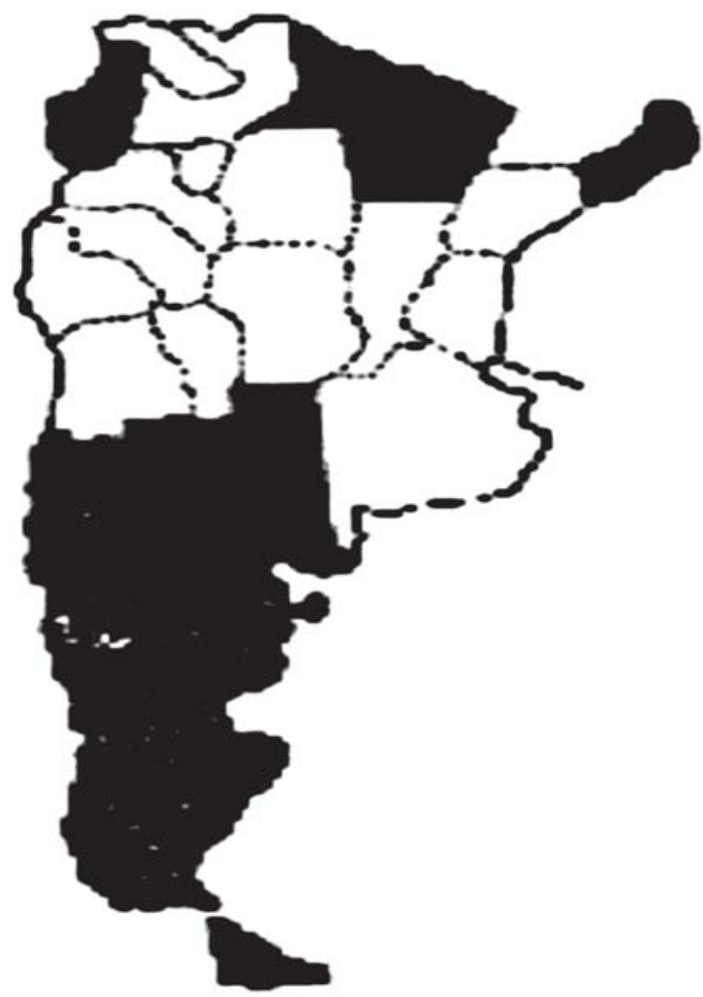

Fuente: Archivo Histórico del Neuquén, Comisión Pro Autonomización del Territorio, 1933. 